\title{
Syria's wind resources: Outlook for the Future
}

\author{
Ahmad Al Jamil $^{*}$, and Gennady Sidorenko ${ }^{1}$ \\ Peter the Great St. Petersburg Polytechnic University, Polytechnicheskaya 29, 195251 St. Petersburg, \\ Russia
}

\begin{abstract}
. 15 locations with wind speeds of more than $5 \mathrm{~m} / \mathrm{s}$ were explored among 24 locations across Syria. Wind data from these locations was analyzed using the Weibull distribution, along with 15 different turbines. Three performance indicators were calculated and compared between each other: annual energy production, power factor $(\theta)$ and energy cost $(\mathrm{z})$. The economic potential was calculated and the economic efficiency of wind turbines was studied on the basis of optimization of wind farm parameters that helped to find an option that provides the lowest price for electricity production on wind turbines. The study reveals that E70 $71 \mathrm{~m} 2300 \mathrm{kw}$ is the optimal turbine in all areas (from the places under consideration), both in terms of the highest efficiency and the lowest energy cost. The results show that the area of Sokhna has the largest economic potential because of the big space suitable for the establishment of wind turbines. Using the proposed wind farm scenario until 2030 is able to cover the deficit by $7.22 \%$.
\end{abstract}

\section{Introduction}

The unstable has conditions in the territory of the Syrian Arab Republic since 2011 have imposed a major challenge from the economic perspectives. The restoration of the national economy, its socio-economic development needs a new sustainable, safe and efficient energy sector of the economy. Various studies show that the remaining oil and gas reserves are limited, and most deposits are difficult to recover [1]. The solution to Syrian energy problems is possible with the large-scale development of renewable energy (primarily solar and wind). Currently, Syria depends on fuel imported from areas that are politically unstable, at high prices and unpredictable in the future. Using local wind resources and choosing the optimal turbine for this place are the most important determinants of the profitability of wind energy investment in a particular area.

The aim of the work is to assess the economic potential of wind energy in Syria and identify the optimal type of wind turbines for this region. A second contribution of this paper is to provide a systematic framework for the economic dimension of wind energy and the energy policy debate when comparing different power generation technologies.

\footnotetext{
* Corresponding author: ahmad.aljamil.sh@gmail.com
} 


\section{Methods}

\subsection{Data}

\subsubsection{Wind Data}

This study uses data of measuring wind speeds from 2 weather stations from the site www.rp5.ru and the data of measuring wind speeds for a certain period at 7 weather stations conducted by the Main Department of Meteorology as initial data. In addition, 15 ready-made velocity distribution functions obtained from the measurement results were used. Measurements were taken by the National Energy Research Center in Syria [1]. By installing wind monitoring stations, each of which has a height of 40 meters (fig.1.). As a result of using various turbines in the specifications, we recalculate the average wind speed $\mathrm{v}\left(\mathrm{h}_{2}\right)$ at different heights depending on the height of the tower [2].

$$
\mathrm{v}\left(\mathrm{h}_{2}\right)=\mathrm{v}\left(\mathrm{h}_{1}\right)\left(\frac{\mathrm{h}_{2}}{\mathrm{~h}_{1}}\right)^{\mathrm{m}}
$$

where $v\left(h_{1}\right)$ - wind speed at the height of regular observational data; $h_{2}$ - estimated height of the axis of the wind wheel; $m$ - Hellman power factor.

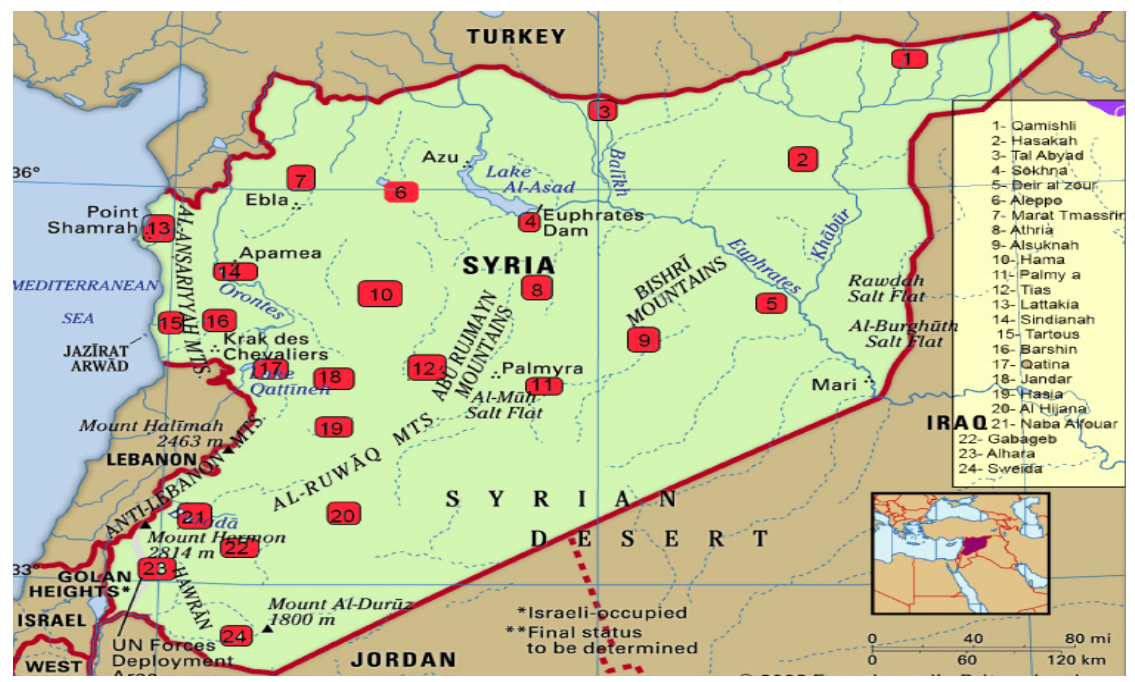

Fig. 1. The used selected locations used in this study.

\subsubsection{Turbine Data}

This study used 15 types of wind turbines from most of the world's leading manufacturers of wind turbines. Figure 2 shows the performance characteristics of wind turbines, which are used in the calculations $[3,4]$. 


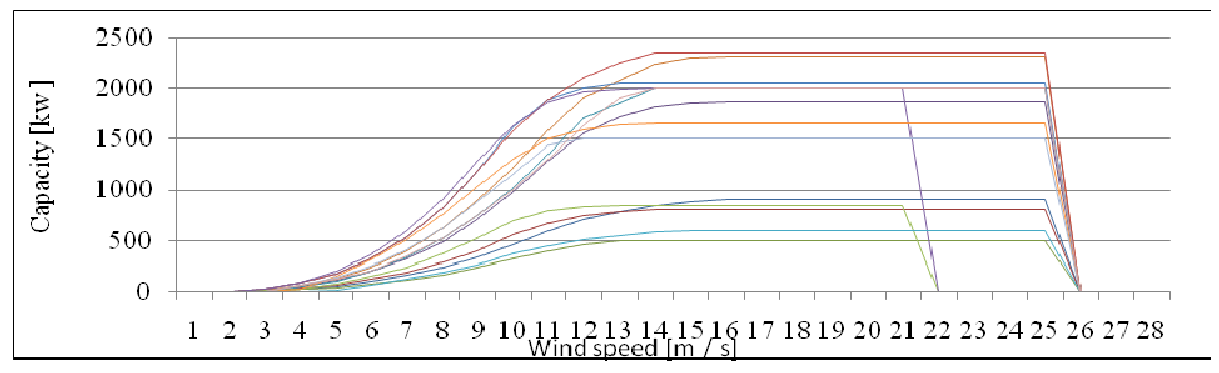

Fig.2. Power curves of all used turbines.

\subsubsection{Power grid Data}

As shown in Figure 3, 15 zones are located in centralized energy supply zones, therefore in this study we will neglect the cost of connecting to grid.

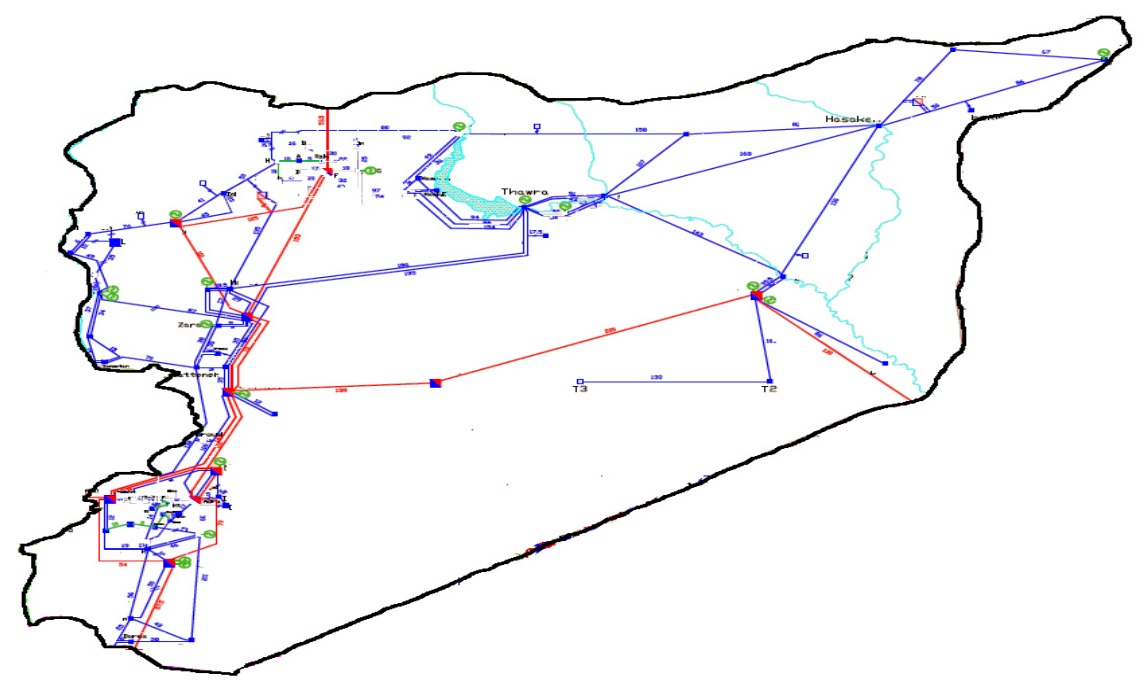

Fig. 3. Map of Electrical Networks and Substations.

\subsection{Cost calculations}

\subsubsection{Costs of setup, operation, maintenance and connection}

The cost of installed capacity of wind energy turbines includes the cost of equipment, transporting it to places of installation and the cost of construction. Determining the cost of turbines, as well as wind data analysis allows us to determine the cost of producing electricity and their effectiveness compared to other power generation techniques.

When comparing different turbines from many manufactures, a better estimate of the price is price per $\mathrm{m}^{2}$ of swept rotor area. The most recent price is around $460 €$ per swept rotor area, with the measure $\mathrm{m}^{2}$. This is almost the same as the long-term average of the index.

Turbines, like any other industrial equipment, require maintenance services, which make up a significant proportion of the total annual cost of wind turbines. However, compared with most other costs of generating electricity, they are very low [5]. Operating 
and maintenance costs are associated with a limited number of cost components and include: Insurance, regular maintenance, repairs, spare parts and administration. According to [6], O \& M costs are $1.5 \mathrm{c} € / \mathrm{kWh}$. According to EWEA, the turbine has a service life of 20 years, in accordance with most technical design criteria. Discount rate is assumed $5 \%$ per annum (EWEA, 2009b) [3, 7, 8].

\subsubsection{Electricity production costs}

The generated electricity is the single most important factor in the cost of generating electricity. Wind resource is one of the most important determinants of the profitability of wind energy investment. In this study we will use the cost of energy to assess the economic feasibility of a particular installation of wind turbines to select the optimal turbine that provides the minimum price of producing the electricity from wind turbine and investment profitability. If $\mathrm{Z}$ is higher than the sale price of electricity, construction will not be possible. The current selling price in Syria is $8 \mathrm{c} € / \mathrm{kWh}$ (Ministry of Electricity / Statistics, 2016).

We further believe that during the lifetime $T_{L}$ and the annual discount rate $d$ is constant, $\mathrm{U}_{\mathrm{t}}{ }^{\mathrm{WPU}}=\mathrm{U}_{\mathrm{E}}{ }^{\mathrm{WPU}}=\mathrm{const}$ and $\mathrm{E}_{\mathrm{t}}{ }^{\mathrm{WPU}}=\mathrm{E}_{\mathrm{G}}{ }^{\mathrm{WPU}}=$ const . Under these assumptions, the cost of electricity produced by wind turbine can be written as $[6,9,10]$ :

$$
\begin{gathered}
\mathrm{z}=\frac{\mathrm{K}^{\mathrm{WPU}} \cdot \mathrm{CRF}\left(\mathrm{d}, \mathrm{T}_{\mathrm{L}}\right)+\mathrm{U}_{\mathrm{E}}{ }^{\mathrm{WPU}}}{\mathrm{E}_{\mathrm{G}}{ }^{\mathrm{WPU}}}, \\
\theta=\frac{\mathrm{N}_{\mathrm{AC}}{ }^{\mathrm{WPU}}}{\mathrm{N}_{\mathrm{IC}}{ }^{\mathrm{WPU}}}, \\
\mathrm{E}_{\mathrm{G}}{ }^{\mathrm{WPU}}=\mathrm{N}_{\mathrm{AC}}{ }^{\mathrm{WPU}} \cdot \mathrm{T}_{=} \mathrm{N}_{\mathrm{IC}}{ }^{\mathrm{WPU}} \cdot \mathrm{T}_{\mathrm{U}}=\theta \cdot \mathrm{N}_{\mathrm{IC}}{ }^{\mathrm{WPU}} \cdot \mathrm{T},
\end{gathered}
$$

Revenue from the sale of electricity $B_{E}{ }^{W P U}$ is determined by the formula:

$$
\begin{gathered}
\mathrm{B}_{\mathrm{E}}{ }^{\mathrm{WPU}}=\mathrm{E}_{\mathrm{G}}{ }^{\mathrm{WPU}} \cdot \mathrm{C}_{\mathrm{TF}}-\mathrm{U}_{\mathrm{E}}{ }^{\mathrm{WPU}}, \\
\mathrm{T}_{\mathrm{PB}}=\frac{\mathrm{K}^{\mathrm{WPU}}}{\mathrm{B}_{\mathrm{E}}{ }^{\mathrm{WPU}}} .
\end{gathered}
$$

The economic effect of using wind turbine NPV is expressed in dollar or ruble and can be defined as the revenue, received from the use of wind turbine through time-life $[6,10]$ :

$$
N P V=\frac{B_{E}{ }^{W P U}}{C R F}-K^{W P U}
$$

\section{Results}

\subsection{Wind Analysis}

Figure 3 shows 15 zones (in green) that are suitable for using wind energy. Parshin has the highest average annual wind speed over the measured period, an average of $8.1 \mathrm{~m} / \mathrm{s}$ ). 


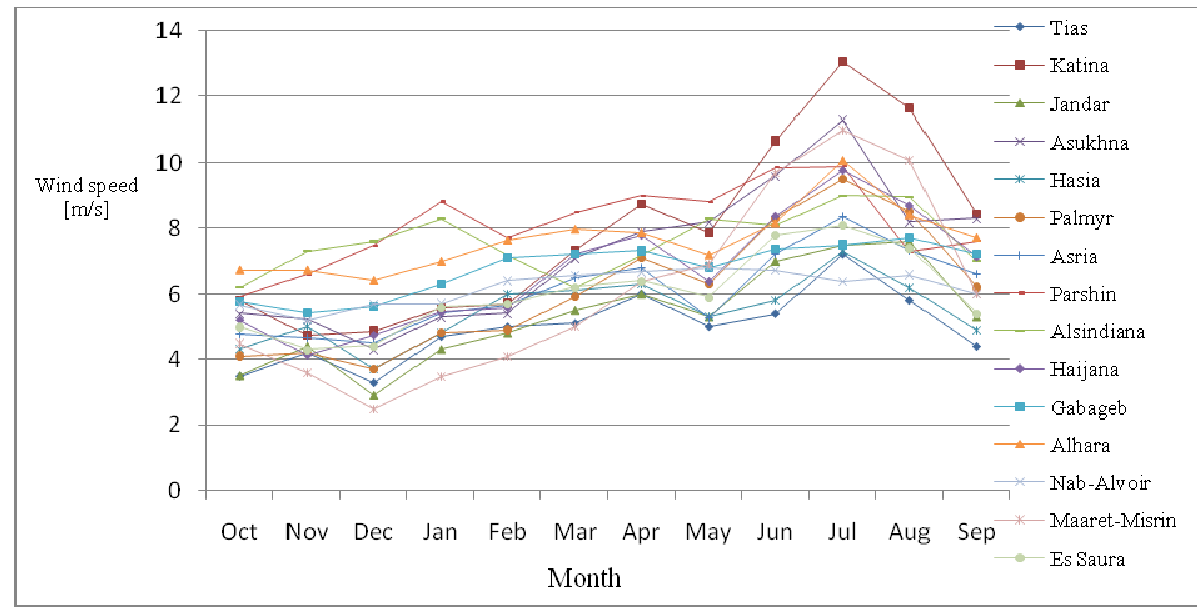

Fig. 4. Average monthly wind speed for 15 stations a height of $40 \mathrm{~m}$.

\subsection{Annual Energy Output}

Turbines Enercon E82 E2 82m 2000k, Enercon E82 82m 2300kw and Gamesa G90 2.0MW generate approximately the same amount of electricity with a slight superiority of turbines Enercon E82 $82 \mathrm{~m} 2300 \mathrm{kw}$ in most regions, for example, this turbine in the Alsindiana zone gives $10.54 \mathrm{GWh} /$ year, whereas turbines Enercon E82 E2 82m 2000kw and Gamesa G90-2.0MW give 10.02 and $10.09 \mathrm{GWh} /$ year, respectively.

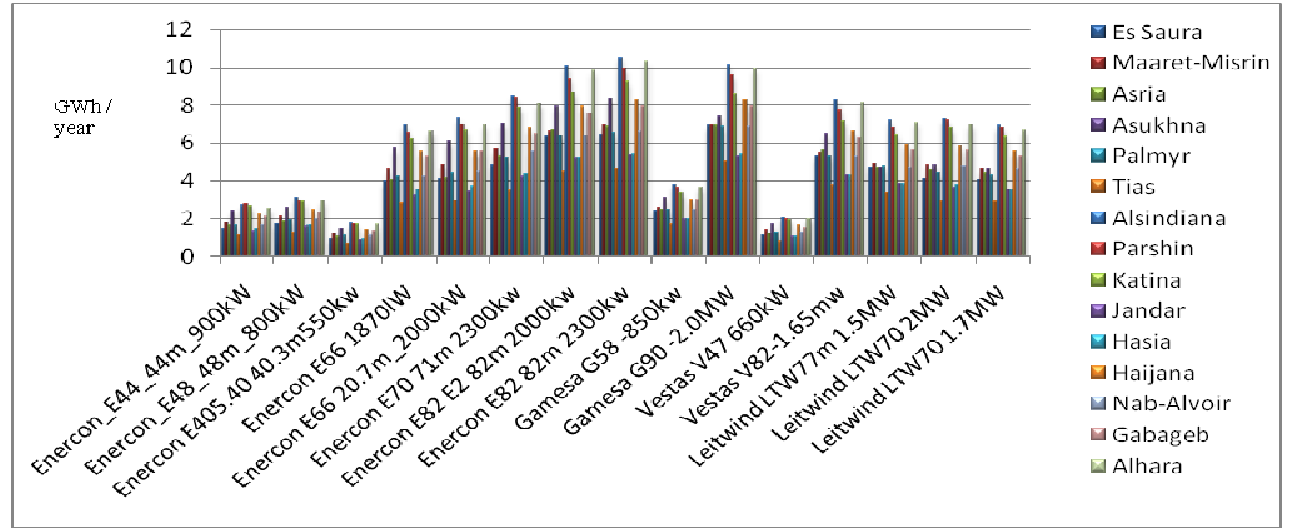

Fig. 5. Annual energy production for all turbines.

\subsection{Maximum Capacity Factor}

As shown in Figure 6, the Gamesa G90 -2.0MW is the turbine giving the highest average power factor among all turbines, and the Vestas V47 660kW is the lowest. 


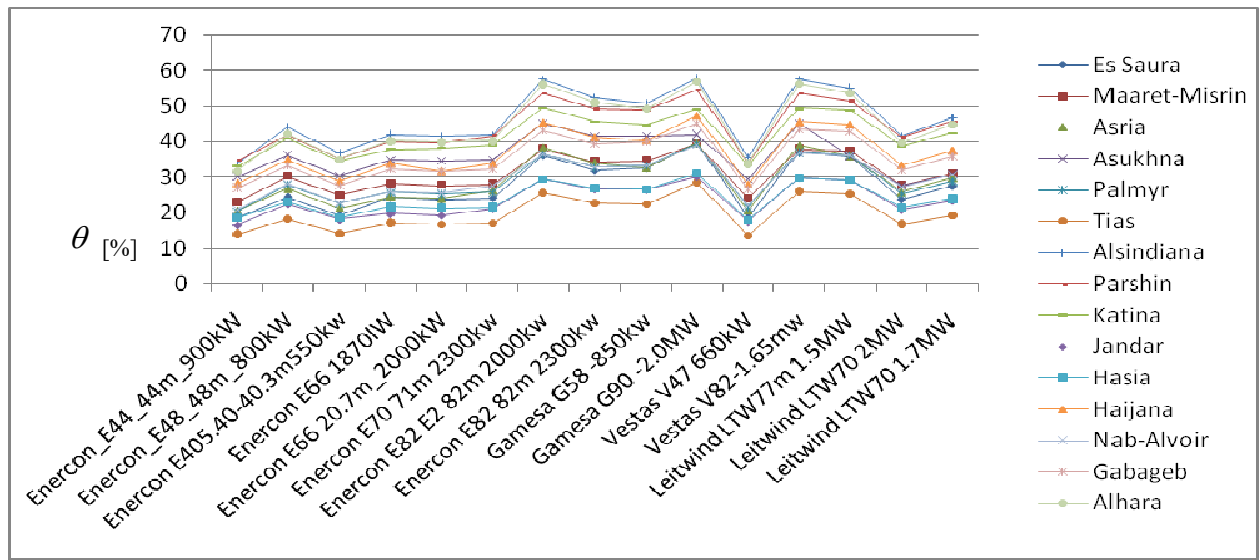

Fig. 6. Power factors for all turbines in all locations.

\subsection{Minimum Cost of Energy}

Cost of energy $(\mathrm{Z})$, measured in $\mathrm{c} € / \mathrm{kWh}$. Alsindiana is the location giving the lowest mean cost over all the turbines and Tias gives the highest. The turbine that gives the lowest $\mathrm{Z}$ is Enercon E70 $71 \mathrm{~m} 2300 \mathrm{kw}$. This means that the turbine that have the highest capacity factors are not the one giving the lowest $Z$. The reason is that large rotor turbines generally have high capacity factor but as cost is related to rotor size, the capital cost is negatively affected by the large rotor. The higher energy output of the Gamesa G90 -2.0MW does not compensate for its higher installation cost [3].

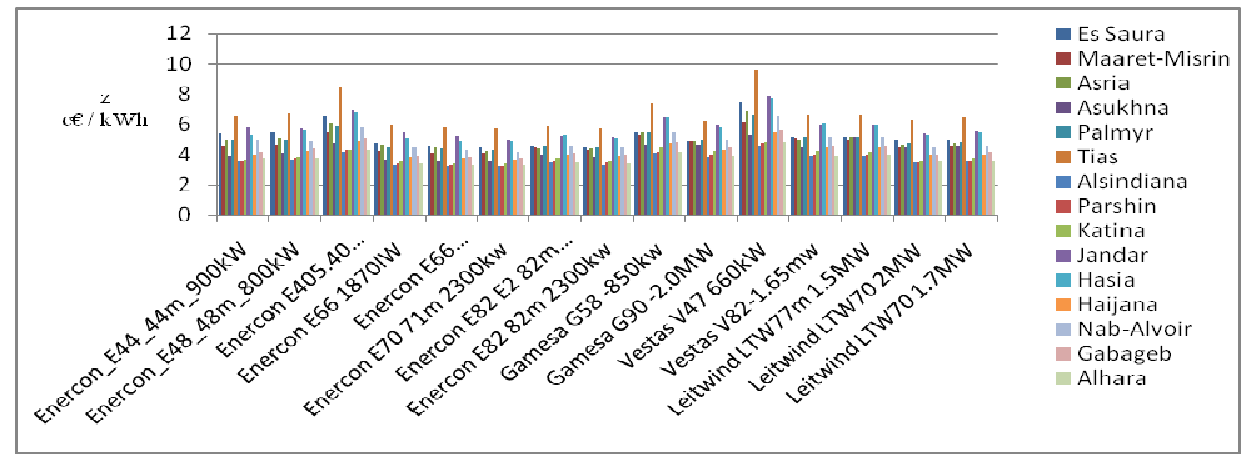

Fig. 7. Energy cost for all turbines. 


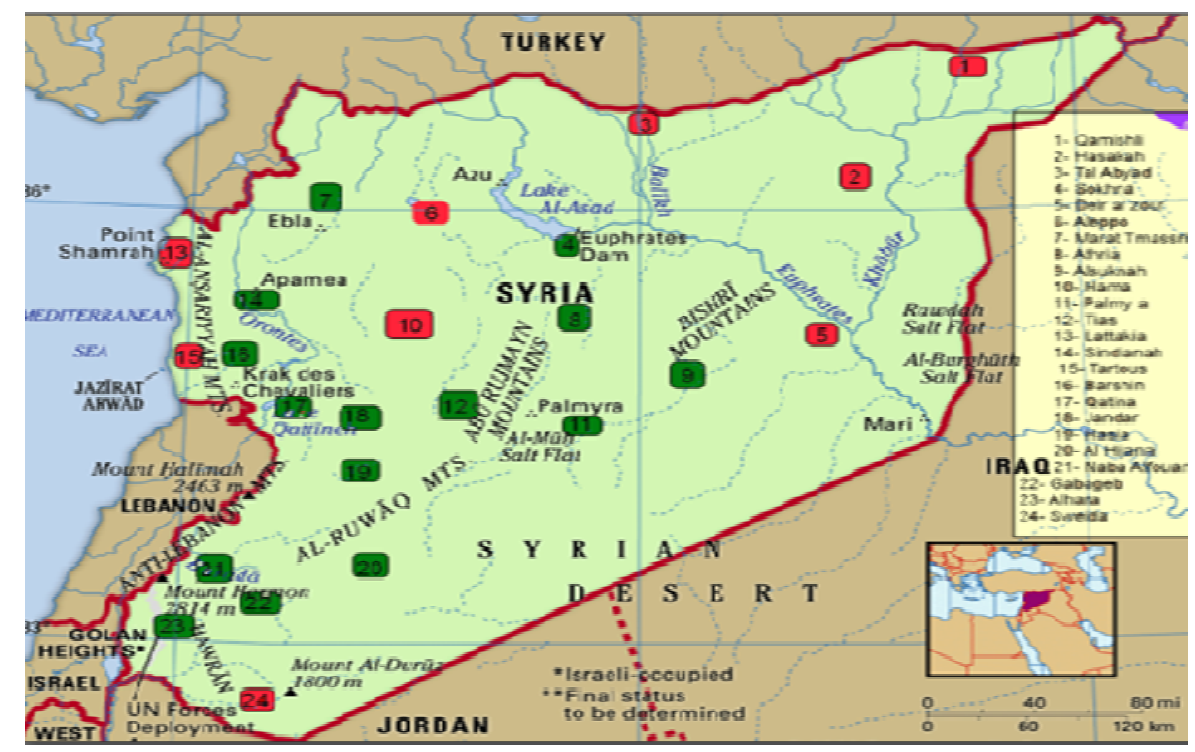

Fig. 8. Promising wind farms in Syria.

\subsection{The simple payback $T_{\mathrm{PB}}$ and economic effect of using wind turbine NPV}

As can be seen, the economic indicators that determine the economic feasibility and effectiveness of using wind turbine, are strongly dependent on the amount of electricity generated. For example, in the Al-Sindianiyah region, the amount of electricity generated is $10.492 \mathrm{GW}$ using E70 $71 \mathrm{~m} 2300 \mathrm{kw}$, which increases the economic effect of using wind turbine NPV and reduces the simple payback.

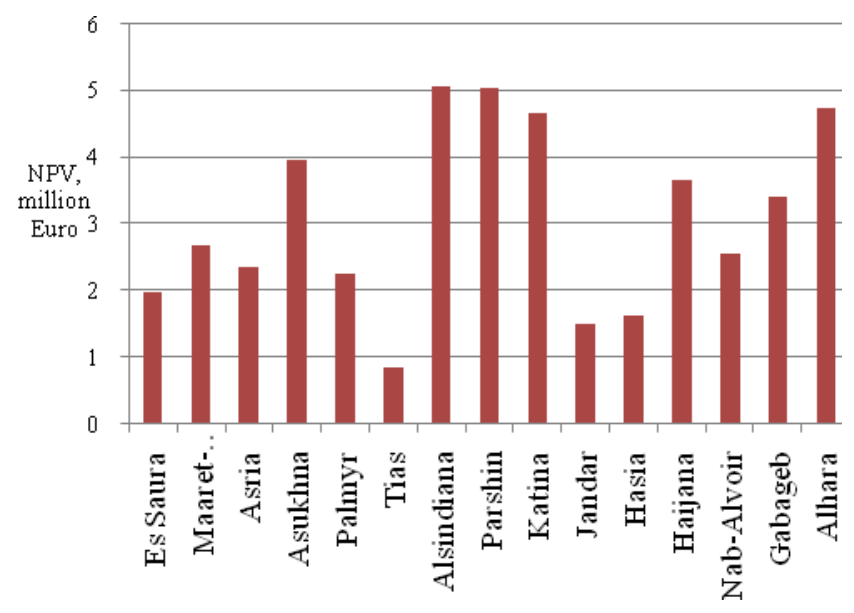

Fig. 9. The economic effect of using wind turbine. 


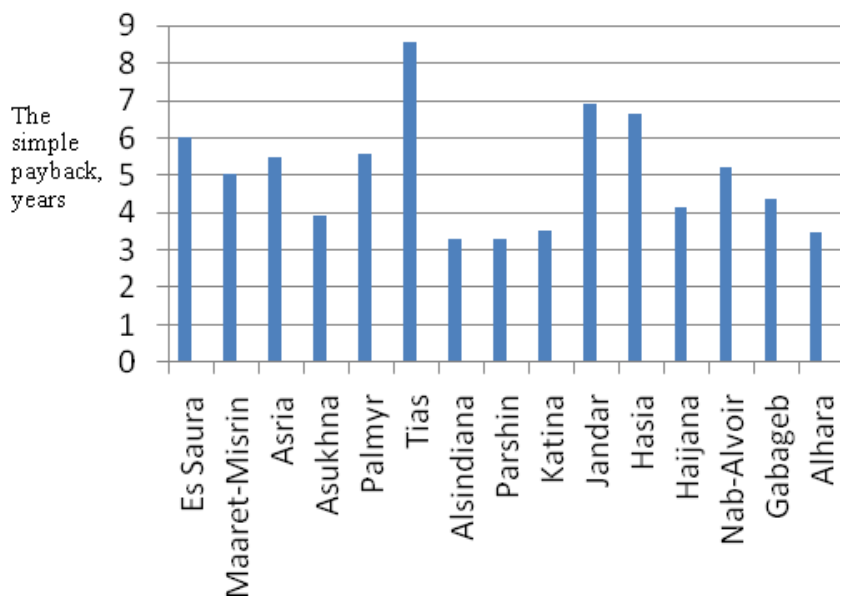

Fig. 10. The Simple payback of wind energy turbine.

\subsection{The expected demand for energy in Syria until 2030 and covering the electric power deficit if the proposed wind farms construction scenario is used}

The expected energy demand was studied in light of a number of assumptions, as it was considered a recovery phase until 2021, where oil and gas resources would be restored and all sectors activity (expected daily production until 2030 around 350 thousand $b / d$, which is equivalent to about 18 Mtoe, natural gas production will reach about 7 Mtoe), i.e. the total available in traditional sources (about 25 Mtoe), the rate of growth of energy demand from 2021 to 2025 is about $5 \%$ and $7 \%$ from 2026 to 2030 . Consequently, demand is expected in 2030 to reach about 41 Mtoe. Each $3 \mathrm{GWh}$ hour equivalent to $750 \mathrm{Toe}$, and therefore to cover the gap of 1 Mtoe, needs $4000 \mathrm{GWh}$.

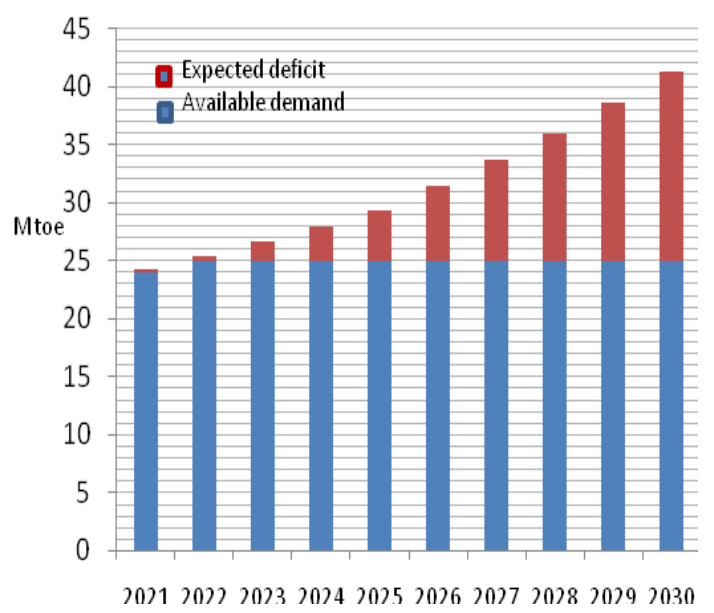

Fig. 11. Primary energy demand and expected deficit from 2021 to 2030 (Mtoe). 
Table 1. Prospective Wind Power Plants of Syria.

\begin{tabular}{|c|c|c|c|}
\hline Name & $\begin{array}{c}\text { The installed } \\
\text { capacity } \\
{[\mathrm{MW}]}\end{array}$ & Energy generation [GWh/year] & $\begin{array}{c}\text { Covering the } \\
\text { electric power } \\
\text { deficit [\%] }\end{array}$ \\
\hline Barshin & 78.2 & 284.6 & 0.44 \\
\hline Sindianah & 85.1 & 312.89 & 0.48 \\
\hline Qatina & 82.8 & 282.86 & 0.44 \\
\hline Alhara & 101.2 & 356.39 & 0.55 \\
\hline Gabageb & 41.4 & 116.9 & 0.18 \\
\hline Alsuknah & 126.5 & 386.87 & 0.60 \\
\hline Athria & 124.2 & 285.6 & 0.45 \\
\hline Jandar & 92 & 169.86 & 0.26 \\
\hline Al Hijana & 96.6 & 285.33 & 0.44 \\
\hline Althawra & 112.7 & 237.67 & 0.37 \\
\hline Marat Tmassrin & 117.3 & 287.16 & 0.45 \\
\hline Palmyra & 128.8 & 289.42 & 0.45 \\
\hline Naba Alfouar & 105.8 & 254.97 & 0.40 \\
\hline Hasia & 105.8 & 199.82 & 0.31 \\
\hline Tias & 103.5 & 155.48 & 0.24 \\
\hline Total : & 1501.9 & 3905.82 & 6.06 \\
\hline
\end{tabular}

Based on the data from table 1 , it is possible to concluded that the use of the proposed wind farm scenario until 2030 is able to cover the deficit by $7.22 \%$ and more, therefore it must be invested as soon as possible, or at least it should start with the construction of the farms in a sequence according to the regions where it is preferable to start building a Hasia, Jandar, Qatina, Al Hijana and Gabageb farm where there is a population density is large alongside industrial cities where the demand for energy is very high.

\subsection{The great importance of the Gbaghb and Al-Harah wind farms in agriculture}

Daraa is considered to be the food basket of Syria [11], where Syria is almost satisfied with wheat and vegetables, and it occupies the first position in the production of tomatoes and vegetables in general. The main difficulties experienced by the agricultural sector since the start of the war in Syria are the lack of an electrical current continuously to extract groundwater, where farmers use pumps that work mostly by the electric current, and as a result of the lack of electric current continuously, the crops may be thirsty or dehydrated in the event of a power outage for a long time. The shortage and high prices of fuel and fuel as a result of the lack of a continuous electricity supply, so many farmers bought electrical generators to use them in the event of necessity to run water pumps, but as a result of the shortage and high prices of fuel, the problem of the lack of electric current has not been radically solved. So the great importance of wind energy investment in Syria, especially in the Al-Harah and the Gbaghb regions.

\section{Conclusions}

The results show that the E70 $71 \mathrm{~m} 2300 \mathrm{kw}$ is the optimal turbine in all areas (from the places under consideration), both in terms of the highest efficiency and the lowest energy cost. In any case, it indicates that it is economically feasible to invest. because the selling price of electricity generated by the wind is $8 \mathrm{c} € / \mathrm{kWh}$. Different turbines are selected as optimal, depending on whether the goal is to maximize power factor or minimize energy 
costs. The economic potential of wind energy is estimated at $4.62 \mathrm{TWh}$ per year. The zone with the greatest economic potential is Zone 9 which located in the east of the country, where there are many deserts.

It should be noted that the stations at which measurements were taken are located very unevenly throughout Syria, mainly concentrated in the western part of the country, which is consistent with the map of population density. However, to obtain a more accurate estimate, uniform distribution of observation stations over the country's area is required.

Bridging the expected energy gap in 2030, estimated at 16 Mtoe, requires a large volume of investments. It is better to apply a scenario (raising the efficiency of the Syrian electrical system (generation - transmission - distribution) + Use of a mix of renewable energies (solar - wind).

\section{References}

1. Annual Statistical Report 2017 Ministry of Electricity, General Directorate for Electric Power Transmission, Electron, (2017) . http://www.pete.gov.sy/

2. J.D. Arbuzov, P.P. Bezrukikh, G.A. Borisov, V.I. Vissarionov, V.M. Evdokimov, N.K. Malinin, N.V. Ogorodov, V.N. Puzakov, G.I. Sidorenko, A.A. Shpak, Resources and efficiency of using renewable energy sources in Russia, 314, (2002)

3. K. Helgason, Selecting optimum location and type of wind turbines in Iceland. Master of Science in Decision Engineering, School of Science and Engineering Reykjavik University, (2012).

4. WindPower Program. http://www.wind-power-program.com

5. H. Holttinen, The Impact of Large Scale Wind Power Production on the Nordic Electricity System, VTT Publications 554, (2004).

6. M. Al-omary, M. Kaltschmitt, C. Becker, Electricity system in Jordan: Status \& prospects, Renewable and Sustainable Energy Reviews 81, 2398-2409, (2018).

7. S. Jacobsson, A. Johnson, "The development of a growth industry - The wind turbine industry in Germany, Holland and Sweden" (2003).

8. C.L. Archer, M.Z. Jacobson, The Spatial and Temporal Distributions of U.S. Winds and Windpower at $80 \mathrm{~m}$ Derived from Measurements, Journal of Geophysical Research: Atmospheres, (2002).

9. G.I. Sidorenko, , A. A. Jamil, Method of Assessing the Economic potential of Wind Energy in the Region (case study Syria), IOP Publishing, IOP Conf. Series: Journal of Physics: Conf. Series 1087, 022016, (2018).

10. A.E. Kopylov, Renewable Energy Economics, 364, (Moscow, 2015).

11. ASTAE (The World Bank's Asia Alternative Energy Program). www.worldbank.org/astae 